\title{
Global left ventricular afterload matters in left ventricular reverse remodeling after aortic valve replacement
}

\author{
Hisato Ito ${ }^{1}$ \\ Received: 4 March 2020 / Accepted: 31 March 2020 / Published online: 7 April 2020 \\ (c) The Japanese Association for Thoracic Surgery 2020
}

It has long been held that effective orifice area (EOA) of a prosthetic valve solely determines left ventricular (LV) mass regression following aortic valve replacement (AVR) for aortic stenosis (AS), and that patient prosthesis mismatch (PPM) is associated with inadequate $\mathrm{LV}$ reverse remodeling and poor prognosis. The degree of LV mass regression, however, varies in individual patients, and even a patient with PPM could achieve significant LV reverse remodeling [1].

Hypertension is commonly seen in patients with AS, and is associated with negative LV remodeling and increased cardiovascular morbidity and mortality [2]. Hypertension is another important component of LV afterload, or vascular load, and is often overlooked. Global LV afterload including both valvular and vascular loads may play a vital role in postoperative $\mathrm{LV}$ reverse remodeling. Valvuloarterial impedance (Zva) is an echocardiographic derived measure of global LV afterload, and is calculated using the formula, $\mathrm{Zva}\left(\mathrm{mmHg} / \mathrm{ml} / \mathrm{m}^{2}\right)=($ systolic blood pressure + mean transvalvular pressure gradient)/stroke volume index [3]. We have shown that Zva is a significant predictor of $\mathrm{LV}$ reverse remodeling after AVR, as opposed to traditional parameters of prosthetic valve function including transvalvular pressure gradients and prosthetic valve EOA [4].

The present study by Hachiro and colleagues showed that postoperative EOA did not correlate with LV reverse remodeling in patients without PPM [5]. Multivariate predictors of LV reverse remodeling were male gender and preoperative LV mass index. Taking Zva into consideration would have led to more reliable results in this patient population. We recently investigated $\mathrm{LV}$ reverse remodeling following aortic valve neocuspidization for AS, which achieves larger EOA than commercially available stented bioprostheses. In

Hisato Ito

hisato.ito@gmail.com

1 Department of Thoracic and Cardiovascular Surgery, Mie University Hospital, 2-174 Edobashi, Tsu, Mie 514-8507, Japan this study, Zva was the multivariate predictor of LV reverse remodeling, but traditional parameters of valvular function were not even in patients with large enough EOA (unpublished data). Global LV afterload seems to add a deeper insight into longstanding debate over who is the key player in postoperative $\mathrm{LV}$ reverse remodeling in patients with and also without PPM after AVR for AS.

\section{Compliance with ethical standards}

Conflict of interest The authors disclose no sources of support or conflicts of interest.

\section{References}

1. Tasca G, Brunelli F, Cirillo M, Dalla Tomba M, Mhagna Z, Troise $\mathrm{G}$, et al. Impact of the improvement of valve area achieved with aortic valve replacement on the regression of left ventricular hypertrophy in patients with pure aortic stenosis. Ann Thorac Surg. 2005;79:1291-6.

2. Rieck AE, Cramariuc D, Boman K, Gohlke-Barwolf C, Staal EM, Lonnebakken MT, et al. Hypertension in aortic stenosis. Implications for left ventricular structure and cardiovascular events. Hypertension. 2012;60:90-7.

3. Briand M, Dumesnil JG, Kadem L, Tongue AG, Rieu R, Garcia D, et al. Reduced systemic arterial compliance impacts significantly on left ventricular afterload and function in aortic stenosis. J Am Coll Cardiol. 2005;46:291-8.

4. Ito H, Mizumoto T, Shomura Y, Sawada Y, Kajiyama K, Shimpo $\mathrm{H}$. The impact of left ventricular afterload on left ventricular reverse remodeling after aortic valve replacement. J Card Surg. 2017;32:530-6.

5. Hachiro K, Kinoshita T, Asai T, Suzuki T. Left ventricular mass regression in patients without patient-prosthesis mismatch after aortic valve replacement for aortic stenosis. Gen Thorac Cardiovasc Surg. 2019;68:227-32.

Publisher's Note Springer Nature remains neutral with regard to jurisdictional claims in published maps and institutional affiliations. 